\title{
Seed Germination of selected Taxa from Kachchh Desert, India
}

\author{
Vinay M. RAOLE, Aruna G. JOSHI, Sandhya K. GARGE, Rinku J. DESAI \\ The Maharaja Sayajirao University of Baroda, Faculty of Science, Department of Botany, Vadodara-390 002, India; vinayraole@yahoo.com
}

\begin{abstract}
The district of Kachchh contains many culturally important plants. However, their conservation status is little known due to direct and indirect human activities. This study was undertaken with the aim of contributing to the conservation of the native species of these semi-arid regions through germination trials under laboratory conditions. Mature fruits of ten selected species were collected randomly from the known habitats to obtain viable seeds. These seeds were pre-treated with growth regulators singly or in combination after acid scarification or without scarification. Seeds were found to be dormant due to presence of thick seed coat or due to low level of endogenous hormonal level. Most of these seeds required different storage period to mature. Only seeds of Capparis cartilaginea germinated without treatment while the other species required treatments. Addition of growth regulators has enhanced seed germination in few taxa singly and in some plant cases in combination.
\end{abstract}

Keywords: Kachchh, selected taxa, seed storage, seed germination, GA, IAA

\section{Introduction}

In spite of the great importance of the Kachchh flora to the vegetation of semiarid regions of India, there are surprisingly few studies that address key processes to plant conservation, as germination characteristics, reproductive biology and autecology. Although efforts for propagating endemic species of Kachchh have been carried out since 1970, only floristic, evaluative and biogeographic studies have been carried out (Sabnis and Rao, 1983; Raole, 1997) while, there were few studies on germination patterns of this flora of semi arid region (Sen and Mohammed, 1991).

Although, the functional aspect of the seed is to germinate and produce its offspring, many desert taxa exhibit some kind of inhibition. Numerous observations on seed germination of desert or semiarid plant taxa emphasized the differences in the germination response to physiological and environmental conditions (Gutterman, 1992; Khan and Ungar, 1997). Besides the theoretical importance and significance of seed germination is very important for the conservation and reproduction of rare and endangered species. Plant conservation and restoration programs require germination information in order to help these fragile species to persist (Porteous, 1993; Akeroyd, 1995; Clemente and Hernández, 1995). It constitutes the key factors that determine the distribution of plant species in space and time (Venable and Lawlor, 1980). Germination attributes of the plant species are correlated with climate, season, and habitat (Angevine and Chabot, 1979). For example, at one end of the spectrum, seeds of many desert plants remain dormant while on the other hand some of them remain buried in the soil, for many years after dispersal, until rainfall is high enough to trigger germination (Venable and
Lawlor, 1980). Between both extremes, in strongly seasonal environments the seeds tend to exhibit a considerable delay of germination until environmental conditions are suitable for seedling establishment (Figueroa et al., 2004). Thus, the period of time that a seed remains viable in the soil, without germinating, is a critical component of the germination strategy of plants in seasonal environments (Figueroa and Armesto, 2001). Following dispersal, seeds may germinate immediately or remain viable in the soil forming a seed bank (Fenner, 1985). Persistent seed banks are ecologically important (Fenner, 1985) they allow maintenance of biodiversity in communities (Bakker et al., 1996; Ozinga et al., 2005) and genetic diversity in populations (Levin, 1990). This can protect populations from local extinction when above-ground vegetation is removed, and hence are important for restoration and conservation purposes (Bakker et al., 1996; Kalisz et al., 1997). In a recent study, Whittle (2006) claims to have found a positive correlation between seed persistence and molecular evolutionary rates.

This study was undertaken to determine the effect of length of time of seed storage under laboratory conditions and the impact of growth promoters on seed germination. With the help of this investigation germination response of some restricted taxa from the semiarid region can be ascertained and survival strategies will be understood. These plants have a restricted distribution and are rare in occurrence in the semi arid land of Kachchh because these plants are not observed commonly in the adjoining areas of Gujarat and Rajasthan state. 
Tab.1. Distribution and uses of some useful plants of in the semi arid land of Kachchh

\begin{tabular}{cccc}
\hline Taxon & Family & $\begin{array}{c}\text { Distribution } \\
\text { In Kachchh }\end{array}$ & Habitat \\
\hline Capparis cartilaginea Decne. & Capparidaceae & Narayan Sarovar, Tera & Crevices of old walls \\
Abutilon indicum L. & Malvaceae & Anjar, Nakhatrana & Fallow fields \\
Abutilon pannossum (Forsk.f.) Schelet. & Malvaceae & Naliya & Dry river banks \\
Pavonia arabica Hochst ex steud. & Malvaceae & Dhinodhar & Exposed hilly slopes \\
Senera incana Cav. & Malvaceae & Nadibaugh, Loriya & Exposed hilly slopes open \\
area on road sides
\end{tabular}

\section{Materials and methods}

Details of distribution and habitat of the plants used for the present research are given in Tab. 1. Fruits were collected between August and December, 2005-2007 from the district of Kachchh. Mature seeds were brought to the department and stored in plastic containers for 2 or more years. Healthy and mature seeds were surface sterilized with $0.1 \%$ aqueous solution of mercuric chloride for about $5 \mathrm{~min}$. washed thoroughly with running water and submerged in distilled water for $24 \mathrm{~h}$ at $25 \pm 2^{\circ} \mathrm{C}$. The seeds were transferred to Petri plates lined with three layers of filter paper made wet with distilled water and allowed to germinate in an incubator at $25 \pm 2^{\circ} \mathrm{C}$, under continuous illumination provided by fluorescent white light. Seeds of the same taxa which did not germinate were subjected to acid scarification for $2 \mathrm{~min}$ and washed with running water prior to germination experiment. $\mathrm{GA}_{3}$ and IAA concentrations of 10, 20 and $30 \mathrm{ppm}$ were tried individually and in combination Germination was carried out on Whatman filter paper with $5 \mathrm{ml}$ of test solution. Three replicates of 25 seeds each were used for each treatment. Observations were recorded every two days for 10 days. The rate of germination and percentage were recorded. Seeds were considered to be germinated only after the emergence of 2 $\mathrm{mm}$ radical.

\section{Results}

Kachchh district is quite interesting as it belongs to arid-semiarid zone due to its peculiar geographical position, extreme climatic conditions and presence of xerophytic plant life forms. Moreover, variation of habitat quality in space and time have crucial effects on the populations and have a higher extinction risk due to unfavorable environmental condition. Presently studied taxa have very small populations and restricted in distribution at specific habitats only. A. indicum, A. pannosum and I. kotschyana were recorded from fallow fields and dry river beds. While, $S$. incana, S. latifolia, P. arabica from exposed hill slopes and
$P$. zeylanican and $P$. grewioides under the thorny scrubs. Where as, C. marrubifolium and C. critica from sandy gravely/saline soil. At the same time, $C$. cartilaginea were observed only from the crevices of the old pond walls only. These are in agreement with the findings of the Sabnis and Rao (1983).

The results obtained for seed germination are shown in Tab. 2 and 3. From Tab. 2 germination percentages started to increase after 5-8 months for $C$. cartilaginea and for other rest of the species after 12 months. C. cartilaginea showed little germination after 5 months but enhanced (40-50\%) germination has been recorded only after 24 months. Similarly, germination period for the other species ranged between 9-16 months. The synergistic effect of storage and the hormonal treatment added a varied impact on the germination status. C. cretica responded to higher concentration of $\mathrm{GA}_{3}$ and $S$. incana and $A$. pannossum to higher concentration of IAA (Tab. 3).

The impact of growth promoters especially IAA was better when compared to $\mathrm{GA}_{3}$. Seed germination was enhanced at the species of taxa after the management of the growth enhancers. Higher germination percentages were recorded for seeds treated with GA and IAA in combination than when used one at a time. Under the influence of $\mathrm{GA}_{3}$ only $A$. pannosum and $S$. incana has shown improved germination. $A$. indicum and $C$. cartilaginea have given better outcome than other species after treatment with IAA only. Even $A$. pannosum and $S$. incana recorded more germination percentage along with the above two species (Tab. 3).

For all studied species it was observed that the IAA responded even at lower concentrations. C. cartilaginea and $S$. incana are two frontrunners among the other species as they have shown better result at lower concentration also. Moreover the synergistic effect of GA3 and IAA sligly increased the respond but this difference was not much from that of IAA in all the studied taxa (Tab. 3). 
Tab. 2. The effect of duration of (seed storage under laboratory condition) on seed germination of selected plant species of Kachchh Desert

\begin{tabular}{|c|c|c|c|c|c|c|c|}
\hline \multirow[t]{2}{*}{$\begin{array}{l}\text { Name of the } \\
\text { plant species }\end{array}$} & \multicolumn{7}{|c|}{ Months } \\
\hline & $0-4$ & $5-8$ & $9-12$ & $13-16$ & $17-20$ & $21-24$ & $25-28$ \\
\hline A. indicam & - & - & $5.6- \pm 0.23$ & $11.8 \pm 0.4$ & $14.4 \pm 0.23$ & $43.4 \pm 0.11^{*}$ & $54.3 \pm 0.34^{* *}$ \\
\hline A.pannosum & - & - & $14.2 \pm 0.12$ & $24.4 \pm 0.45$ & $35.6 \pm 0.5$ & $41.2 \pm 0.12$ & $59.7 \pm 0.3^{* *}$ \\
\hline C. cartilaginea & - & $3.1 \pm 0.3$ & $7.4 \pm 0.43$ & $18.5 \pm 0.32$ & $35.6 \pm 0.56$ & $40.2 \pm 0.34^{*}$ & $58.6 \pm 0.2$ \\
\hline C. marrubifolium & - & - & - & $3.2 \pm 0.17$ & $6.2 \pm 0.54$ & $18.9 \pm 0.4$ & $41.4 \pm 0.34^{*}$ \\
\hline C. critica & - & - & $5.4 \pm-.34$ & $6.3 \pm 0.18$ & $19.7 \pm 0.32$ & $36.7 \pm 0.5^{*}$ & $48.7 \pm 0.12^{* *}$ \\
\hline I. kotschyana & - & - & $6.5 \pm 0.23$ & $11.2 \pm 0.23$ & $17.8 \pm 0.3$ & $29.4 \pm 0.34^{*}$ & $39.8 \pm 0.11$ \\
\hline P. arabica & - & - & - & $8.2 \pm 0.33$ & $10.4 \pm 0.4$ & $22.5 \pm 0.32$ & $45.7 \pm 0.45^{*}$ \\
\hline P. grewioides & - & - & - & $6.6 \pm 0.34$ & $9.4 \pm 0.43$ & $28.7 \pm 0.22^{*}$ & $41.6 \pm 0.5$ \\
\hline P. zeylanica & - & - & - & $3.4 \pm 0.1$ & $8.6 \pm 0.21$ & $18.4 \pm 0.23$ & $35.8 \pm 0.61^{* *}$ \\
\hline S. incana & - & - & - & $4.5 \pm 0.1$ & $11.7 \pm 0.56$ & $24.8 \pm 0.32^{*}$ & $43.8 \pm 0.12^{* *}$ \\
\hline S. latifolia & - & - & - & $2.4 \pm 0.12$ & $10.7 \pm 0.45$ & $23.6 \pm 0.12^{*}$ & $40.1 \pm 0.12$ \\
\hline
\end{tabular}

${ }^{*}$ and ${ }^{* *}$ represent significance at $\mathrm{p}>0.05$ and 0.01 level, respectively

Tab. 3. Effects of storage duration and combined concentrations of $\mathrm{GA}_{3}$, IAA and $\mathrm{GA}_{3}+\mathrm{IAA}$ on seed germination percentage on selected plant species of Kachchh Desert

\begin{tabular}{cccccccccc}
\hline $\begin{array}{c}\text { Name of the } \\
\text { plant species }\end{array}$ & \multicolumn{3}{c}{$\mathrm{GA}_{3} \mathrm{ppm}$} & & \multicolumn{3}{c}{ IAA ppm } & \multicolumn{3}{c}{ GA + IAA ppm } \\
\hline & 10 & 20 & 30 & 10 & 20 & 30 & 10 & 20 & 30 \\
A. indicum & $12.2 \pm 0.12$ & $24.5 \pm 0.32$ & $46.7 \pm 0.4^{*}$ & $27.9 \pm 0.6$ & $40.2 \pm 0.21$ & $54.2 \pm 0.9$ & $32.8 \pm 0.42$ & $43.8 \pm 0.8$ & $61.9 \pm 0.6^{* *}$ \\
A. pannosum & $36.6 \pm 0.34$ & $46.7 \pm 0.21$ & $57.8 \pm 0.21^{* *}$ & $43.3 \pm 0.7$ & $53.9 \pm 0.21$ & $61.3 \pm 0.78^{*}$ & $37.7 \pm 0.32$ & $50.2 \pm 0.14$ & $65.4 \pm 0.54^{* *}$ \\
\hline C. cartilaginea & $40.00 \pm 0.21$ & $46.8 \pm 0.12$ & $58.9 \pm 0.32^{*}$ & $39.4 \pm 0.43$ & $46.7 \pm 0.44$ & $55.6 \pm 0.5$ & $41.6 \pm 0.21$ & $52.7 \pm 0.21$ & $65.4 \pm 0.3$ \\
\hline C. marrubifolium & $8.5 \pm 0.2$ & $15.5 \pm 0.2$ & $34.7 \pm 0.28^{*}$ & $5.7 \pm 0.12$ & $19.9 \pm 0.43$ & $34.8 \pm 0.21$ & $23.5 \pm 0.5$ & $31.6 \pm 0.43$ & $44.8 \pm 0.32^{* *}$ \\
\hline C. critica & $8.5 \pm 0.34$ & $18.5 \pm 0.21$ & $30.7 \pm 0.31$ & $9.7 \pm 0.17$ & $29.9 \pm 0.34$ & $44.8 \pm 0.28$ & $25.5 \pm 0.34$ & $34.6 \pm 0.12$ & $54.8 \pm 0.12^{*}$ \\
\hline I. kotschyana & $22.7 \pm 0.31$ & $29.7 \pm 0.37$ & $39.7 \pm 0.12^{*}$ & $20.7 \pm 0.15$ & $30.7 \pm 0.34$ & $38.7 \pm 0.21^{* *}$ & $34.7 \pm 0.34$ & $41.6 \pm 0.3$ & $53.7 \pm 0.8^{*}$ \\
\hline P. arabica & $28.1 \pm 0.26$ & $33.4 \pm 0.4$ & $41.5 \pm 0.27$ & $29.7 \pm 0.16$ & $34.9 \pm 0.43$ & $45.5 \pm 0.32$ & $32.4 \pm 0.42$ & $48.2 \pm 0.6$ & $58.6 \pm 0.4$ \\
\hline P. grewioides & $21.1 \pm 0.6$ & $37.6 \pm 0.43$ & $39.9 \pm 0.15^{* *}$ & $28.6 \pm 0.32$ & $38.5 \pm 0.34$ & $47.6 \pm 0.7$ & $30.1 \pm 0.62$ & $42.2 \pm 0.7^{*}$ & $57.9 \pm 0.33^{* *}$ \\
\hline P. zeylanica & $24.1 \pm 0.31$ & $37.7 \pm 0.45$ & $39.9 \pm 0.2$ & $26.8 \pm 0.23$ & $38.7 \pm 0.76^{*}$ & $44.7 \pm 0.5$ & $27.6 \pm 0.36$ & $39.8 \pm 0.5$ & $49.9 \pm 0.43$ \\
S. incana & $41.7 \pm 0.2$ & $49.8 \pm 0.6$ & $59.8 \pm 0.12^{*}$ & $37.8 \pm 0.34$ & $47.8 \pm 0.45$ & $58.7 \pm 0.21^{* *}$ & $48.9 \pm .41$ & $57.4 \pm .43$ & $65.8 \pm .7^{*}$ \\
\hline S. latifolia & $28.6 \pm 0.34$ & $34.6 \pm 0.23$ & $41.8 \pm 0.34^{*}$ & $28.9 \pm 0.3$ & $37.3 \pm 0.3$ & $48.9 \pm 0.5^{* *}$ & $22.8 \pm .32$ & $39.8 \pm .22$ & $52.4 \pm .12^{*}$ \\
\hline
\end{tabular}

${ }^{*}$ and ${ }^{* *}$ represent significance at $\mathrm{p}>0.05$ and 0.01 level, respectively

\section{Discussion}

The present study has brought out certain facts with respect to this vital component of the plant i.e. the seed. The need of either seed storage or specific hormonal treatment in breaking the seed dormancy has been clearly highlighted. The breaking of seed dormancy inherent or induced due to the environmental stress by application of the growth regulators such as $\mathrm{GA}_{3}$ and IAA has already been shown by several researchers (Evenari, 1985; Sen and Mohammad, 1987). The failure of seed germination, even after the imbibitions of water clearly suggest the existence of seed dormancy. The inability of these seeds to germinate may be due to physiologically immature embryos, presence of inhibitors, low level of endogenous hormones and thick seed coat. Hence, the germination is not possible in nature as suggested by earlier reports (Evenari, 1984; Kasera and Sen, 1992a; Gutterman. 1992). The germination of seeds after the acid scarification is in accordance with earlier reports (Gutterman, 1994). Impact of aging in combination of storage for more than 6-15 months has enhanced the germination percentage in desert plant taxa (Kasera and Sen, 1992b, 1992c; Gutterman, 2000). Germination percentage of these seeds got affected when placed under laboratory conditions. In some taxa the significant decrease in germination has been noticed with increase in storage period was reported in the present experimental studies, which is supported in case of $C$. cartilaginea and $A$. pan- 
44

nossum. Rest other taxa failed to show the same trend of the relation between the storage and germination percentage.

Germination is a prerequisite stage and seed therefore are the most critical component of the life history of annual and perennial semi arid plants, They permit the species to avoid the stress over the course of its life cycle as dormant dispersal units Most seeds do not germinate in soil even after the rain or in soil even in non saline condition. Following dispersal, seeds may germinate immediately or remain viable in the soil forming a seed bank (Fenner, 1985). These seed banks have been classified as transient or persistent (Thompson and Grime, 1979) in accordance with the time that seeds remain viable in the soil. Transient seed banks are those in which all seeds either germinate or lose viability within the same year of production. In persistent seed banks none, or a variable, fraction of seeds germinate during the first year, with Seed banks can protect populations from local extinction when above-ground vegetation is removed, and hence are important for restoration and conservation purposes (Bakker et al., 1996; Kalisz et al., 1997).

The stimulation of germination of seeds noticed under the influence of the GA and IAA clearly suggest the presence of extremely low level $\mathrm{pH}$ these hormones in mature seeds of the desert plant taxa. The marginal improvement of the seeds may be due to a slight additive effect of these hormones as suggested by the earlier reports. Gibbrelic acid is found to be very effective in alleviating innate as well as environmental seed dormancy as reported by Khan and Ungar (1997).

Apparently, seed coat hardness seems to be involved in dormancy besides a requirement for after-ripening. During the after-ripening period of seeds, correlated with a longer duration in natural conditions $\mathrm{GA}_{3}$ as well as IAA synthesis might be stimulated to an extent necessary for dormancy removal. The foregoing account indicates that different plants of the same locality vary as far as the requirements for seed dormancy removal are concerned. Obviously, a population-specific characterization of seed behaviour would be essentially crucial for in situ conservation. Thus, the present data could have implications for conservation and cultivation of the studied populations of restricted plant taxa from Kachchh.

\section{Conclusion}

In the present study, we have tried to establish the relationship between the growth regulators and the germination of the restricted taxa from the Kachchh desert. Under unpredictable distribution, intermittent and irregular rain, as well as massive seed predation, these species might have developed complementary sets of survival strategies. One of the strategies is the germination plasticity, as seed germination percentage was influenced by biotic and abiotic environmental factors. $20 \%$ of the studied species germinated immediately, while $80 \%$ had a delayed germination. Addition of growth regulators has enhanced seed germination in $A$. pannosum and $S$. incana when treated singly and in A. indicum, A. pannosum, C. cartilaginea and $S$. incana in combination. Hence, the synergistic effect of the $\mathrm{GA}_{3}$ and IAA helps them to overcome the dormancy. Only S. latifolia and C. marrubifolium depicted the relationship between the storage period and percent of germination. The result can be utilized for the conservation and maintenance strategy of the restricted and rare flora.

\section{References}

Akeroyd, J. (1995). How to reintroduce a plant successfully. Plant Talk 2:14-15.

Angevine, M. W. and B. F. Chabot (1979). Seed germination syndromes in higher plants. In: O. Solbrig, S. Jain, G. Johnson and P. Raven (Eds.) Topics in plant population biology, Columbia University Press, New York, USA. pp.188-206.

Arroyo, M. T. K., P. Chacon and L. A. Cavieres (2006). Relationship between Seed Bank Expression, Adult Longevity and Aridity in Species of Chaetanthera (Asteraceae) in Central Chile. Ann. Bot. 98:591-600.

Bakker, J. P., P. Poschlod, R. J. Strykstra, R. M. Bekker and K. Thompson (1996). Seed banks and seed dispersal: important topics in restoration ecology. Acta Bot. Neer. 45:461-490.

Clemente, M. and E. Hernández (1995). A conservation plan for the Andalucian flora. Plant Talk 2:16-18.

Evenari, M. (1984). Seed Physiology: From Ovule to maturing seed. Bot. Rev. 50:143-170.

Evenari, M. (1985). The desert environment. In: Evenari, M., I. Noy-Meir and D. W. Goodall (Eds.). Ecosystems of the world, Vol 12A. Hot deserts and arid shrublands. Elsevier, Amsterdam. pp.1-22.

Fenner, M. and K. Thompson (2005). The ecology of seeds. Cambridge University Press, Cambridge.

Figueroa, J. A., J. J. Armesto and J. F. Hernández (1996). Estrategias de germinación y latencia de semillas en J.J. especies del bosque templado de Chiloé, Chile. Revista Chilena de Historia Natural 69:243-251.

Figueroa, J. A. and J. J. Armesto (2001). Community-wide germination strategies in a temperate rainforest of Southern Chile: ecological and evolutionary correlates. Aus. J. Bot. 49: 411-425.

Figueroa, J. A., P. León-Lobos, L. A. Cavieres, H. Pritchard and M. Way (2004). Ecofisiología de semillas en ambientes contrastantes de Chile: un gradiente desde ecosistemas desérticos a templado-húmedos. In: Fisiología ecológica en plantas. Mecanismos y respuesta a estrés en los ecosistemas H. Cabrera (Ed.), Ediciones Universitarias de Valparaíso, Pontificia Uni-versidad Católica de Valparaíso, Chile. pp.8198.

Gutterman, Y. (1992). Survival strategies of annual desert plants. Springer-Verlag, Amsterdam 
Gutterman, Y.(1994)Strategies of seed dispersal and germination in plants inhabiting deserts. Bot. Rev. 60:373-425.

Gutterman, Y. (2000) Environmental factors and evolution of survival strategies of annual plant species occurring in the Negev Desert, Israel. Plant Sp. Bio. 15:113-125.

Kalisz, S., L. Horth and M. A. McPeek (1997). Fragmentation and the role of seed banks in promoting persistence of Collinsia verna in isolated populations. In: Schwartz, M. (Ed.). Conservation in highly fragmented landscapes. New York, NY: Chapman and Hall. pp.268-312.

Karseen, C. M. (1981) Environmental conditions and endogenous mechanism in secondary dormancy of seeds. Isr. J. Bot. 29:45-64.

Kasera, P. K. and D. N. Sen (1992a). Effect of different nitrates on seed germination of Chenopodium spp. (Linn.). Ann. Arid Zone. 31: 75-76.

Kasera, P. K. and D. N. Sen (1992b). Effect of storage on seed germination of some weeds in Indian arid zone. J. Ind. Bot. Soc. 71:123-124.

Kasera, P. K. and D. N. Sen (1992c). Effect of mechanical and acid scarifications on seed germination of some weeds of Indian arid zone. Sci. and Cult. 58:77-78.

Khan, M. M. and I. A. Ungar (1985). The role of hormones in regulating the germination of polymorphic seeds and early seedling growth of Atriplex triangularis Willd. Under saline conditions. Physilogia plantarum 63:109-113.

Khan, M. M. and I. A. Ungar (1997). Alleviation of seed dormancy in the desert forb Zugophyllum simplex L. from Pakistan. Ann. Bot. 80:395-400.

Levin, D. A. (1990). The seed bank as a source of genetic novelty in plants American Naturalist 135:563-572.
45

Ozinga, W. A., J. H. J. Schamine, R. M. Bekker, S. Bonn, P. Poschlod and O. Tackenberg (2005). Predictability of plant community composition from environmental conditions is constrained by dispersal limitation. Oikos. 108:555-561.

Porteous, T. (1993). Native forest restoration. A practical guide to landowners. Queen Elizabeth II National Trust, Wellington, New Zealand. pp.184.

Raole, V. M. (1997). Survival strategies of rare and restricted plant taxa from Kutch, Gujarat. Proc. Nat. Coff. Dimen. Environ. Stress, India. pp.139-141.

Sabnis, S. D. and K. S. S. Rao (1983). Observation of some rare and endangered emdemics of South eastern Kutch. In: Jain, S. K. and R. R. Rao (Eds.) Treatened Plants of India. pp.7177.

Sen, D. N. and S. Mohammad (1991). Marvels of seeds. Geobioss International, Jodhpur.

Thompson, K. and J. P. Grime (1979). Seasonal variation in seed banks of herbaceous species in ten contrasting habitats. Journal of Ecology. 67:893-921.

Ungar, I. A. (1997). Ecophysiology of Vascular Halophytes. Baton Rouge, CRC Press.

Venable, D. L. and L. Lawlor (1980). Delayed germination and dispersal in desert annuals: escape in space and time. Oecologia 46:272-282.

Venable, D. L. and J. S. Brown (1988). The selective interactions of dispersal, dormancy and seed size as adaptations for reducing risk in variable environments. Ame. Nat. 131:360384.

Whittle, C. A. (2006). The influence of environmental factors, the pollen: ovule ratio and seed bank persistence on molecular evolutionary rates in plants. J. Evo. Bio. 19(1):302-308. 